\title{
Optimization of 2-dimensional gel electrophoresis for proteomic studies of solid tumor tissue samples
}

\author{
XU LIANG $^{1}$, JING-RONG WANG ${ }^{1}$, KAM-WAI V. WONG ${ }^{1}$, WEN LUAN HSIAO ${ }^{2}$, HUA ZHOU $^{1}$, \\ ZHI-HONG JIANG ${ }^{1}$, KIN TING R. KAM ${ }^{1}$ and LIANG LIU ${ }^{1}$ \\ ${ }^{1}$ State Key Laboratory of Quality Research in Chinese Medicine/Macau Institute for Applied Research in \\ Medicine and Health, Macau University of Science and Technology, Taipa, Macau 999078, Macau SAR; \\ ${ }^{2}$ School of Chinese Medicine, Hong Kong Baptist University, Kowloon Tong, \\ Kowloon, Hong Kong 999077, SAR, P.R. China
}

Received May 31, 2013; Accepted September 16, 2013

DOI: $10.3892 / \mathrm{mmr} .2013 .1815$

\begin{abstract}
The method of 2-dimensional gel electrophoresis (2-DE) has been widely used for the proteomic profiling of solid biological samples, however, the analytical conditions have not been optimized. The present study optimized the major conditions of 2-DE for determining the protein contents of solid tumor tissues, through enhancement of the separation efficiency and resolution. Three major analytical conditions of 2-DE analysis, namely protein extraction, focusing time for isoelectric focusing (IEF), and pre-reduction and alkylation prior to IEF, were carefully examined so that the optimal parameters and procedures were achieved. The use of a bead mill for protein extraction resulted in a higher protein yield in a minimal processing time. An optimal focusing time for IEF was established which improved the 2-DE image quality and reproducibility. Furthermore, reduction and alkylation of the protein sample prior to IEF reduced the horizontal streaking caused by oxidation and improved the resolution at the cathode. The optimized 2-DE analysis enabled the detection of $20 \%$ more protein spots compared with the previous reported conditions, with higher image quality and reproducibility. Accordingly, the optimized conditions may be used in the 2-DE analysis of tumor tissue samples, by which novel biomarkers of cancerous diseases and molecular targets of drugs are expected to be identified.
\end{abstract}

Correspondence to: Professor Liang Liu or Dr Kin Ting R. Kam, Room N508, Library Building, Macau University of Science and Technology, Avenida Wai Long, Taipa, Macau 999078, Macou SAR, P.R. China

E-mail: 1liu@must.edu.mo

E-mail: ktkam@must.edu.mo

Key words: 2-dimensional gel electrophoresis, proteomics, tumor, optimization method

\section{Introduction}

Two-dimensional gel electrophoresis (2-DE), a technical tool possessing the ability to separate complex protein mixtures with high resolution, has been widely employed for protein profiling studies since the mid-1970s $(1,2)$. It is also the major method used in comparative proteomic studies to screen biomarkers and identify molecular targets of drug actions, as it enables differentially expressed proteins between different groups to be readily visualized. However,optimization studies of the 2-DE method have not yet been conducted, particularly regarding the analytical conditions and procedures of protein extraction, duration of isoelectric focusing (IEF) and reduction and alkylation reaction.

The 2-DE experiment was divided into three major steps: The extraction of proteins from tissues or cells; first-dimension (1D) separation based on protein isoelectric points $(\mathrm{p} I)$ using IEF; and the second-dimension (2D) separation based on protein molecular weight using sodium dodecyl sulfatepolyacrylamide gel electrophoresis (SDS-PAGE) (3). Of these, protein extraction and 1D separation are the most crucial steps for optimizing 2-DE analysis. During protein extraction, a number of proteins may be non-specifically lost or degraded, leading to variability of results in 2-DE analysis. In 1D separation, immobilized $\mathrm{pH}$ gradient (IPG) strips with different lengths are used according to the specific purposes of the study. For instance, the shorter strips $(7,11$ and $13 \mathrm{~cm})$ usually result in faster and cost-effective screening, but the protein loading capacity is limited and the quantitation and identification of particular spots may be compromised due to spot overlapping (4). The longer strips (17, 18 and $24 \mathrm{~cm}$ ), which are designed for maximizing resolution and loading capacity, allow the improved detection of spots and easier selection and identification of the proteins in the map. In addition, the alkylation of amino acid residues by cross-linkers during IEF processes may be non-specifically induced (5). Therefore, conditions in these procedures require optimization.

In the 2-D gel analysis of tumor tissue samples, it is particularly difficult to achieve acceptable resolution using the existing 2-DE protocols due to the multicellularity of tumor tissues. To date, 2-D gel methods performed on tumor tissue proteomes 
have been, generally, based on the existing procedures. In the present study, the key steps of sample preparation, reduction and alkylation, and the 1D separation process in 2-DE analysis on 24-cm strips were optimized for the 2-DE images of proteins in mouse tumor tissue samples. The optimized conditions provide a valuable tool for identifying novel biomarkers of diseases and the underlying molecular mechanisms and targets of drugs.

\section{Materials and methods}

Establishment of a lung cancer model in mice. The LLC-1 cells were obtained from the American Type Culture Collection (Rockville, MD, USA). Male C57BL/6J mice $(n=12)$ at the age of 6-8 weeks were obtained from The Chinese University of Hong Kong (Hong Kong, China). Animal care and treatment procedures conformed to the Institutional Guidelines and Animal Ordinance (Department of Health, HKSAR). The LLC-1 cells harvested from in vitro culture were adjusted to a concentration of $1.5 \times 10^{7}$ cells $/ \mathrm{ml}$ and $0.1 \mathrm{ml}$ cell suspension was injected subcutaneously into the dorsal region of the male C57BL/6J mice. After 21 days, the mice were sacrificed and their tumor tissues were dissected and isolated for frozen storage at $-80^{\circ} \mathrm{C}$. The animal experiment was approved by the ethics committee of Macau University of Science and Technology (Macau, China).

Protein extraction from tumor tissues. Tumor tissues (50 mg) were washed with distilled water three times and protein extraction was performed by one of the following four procedures. i) Bead mill-based protein extraction using a TissueLyser LT (Qiagen, Hilden, Germany): Proteins in the mouse tumor tissues were extracted using TissueLyser LT (Qiagen): Proteins in the mouse tumor tissues were extracted using TissueLyser for $2 \mathrm{~min}$ at $50 \mathrm{~Hz}$ with two metal beads with urea/thiourea lysis buffer [7 $\mathrm{M}$ urea, $2 \mathrm{M}$ thiourea, $4 \%$ (w/v) CHAPS, $30 \mathrm{mM}$ Tris/HCl, $\mathrm{pH} 9.0 ; 1: 10 \mathrm{w} / \mathrm{v}]$ and urea lysis buffer [8 M urea, $4 \%$ (w/v) CHAPS, $30 \mathrm{mM}$ Tris/HCl, pH 9.0; 1:10 w/v], respectively. ii) Homogenization-assisted protein extraction: The tumor tissues were cut into fine pieces and homogenized with urea/thiourea lysis buffer $(1: 10 \mathrm{w} / \mathrm{v})$. iii) Sonication-assisted protein extraction: The tumor tissues were sonicated (10 strokes, low amplitude) with urea/thiourea lysis buffer (1:10 w/v) on ice. iv) Grinding-assisted protein extraction: The frozen tumor tissues were ground to a fine powder under liquid nitrogen and then immediately suspended in urea/thiourea lysis buffer $(1: 10 \mathrm{w} / \mathrm{v})$.

The lysates obtained by each of the four techniques were incubated on ice for $5 \mathrm{~min}$ and centrifuged at $17,000 \mathrm{x} \mathrm{g}$ at $4^{\circ} \mathrm{C}$ for $1 \mathrm{~h}$. The supernatants were collected and $200 \mu \mathrm{l}$ of the extracts was precipitated with a 2-D Clean Up kit (GE Healthcare, Chalfont St. Giles, UK) according to the manufacturer's instructions, or with ice-cold acetone. The pellets were resuspended in urea/thiourea lysis buffer and the protein concentration was determined using a 2-D Quant kit (GE Healthcare). The protein concentration was adjusted to $5 \mu \mathrm{g} / \mu \mathrm{l}$.

\section{$2-D E$}

Rehydration. For rehydration, the existing procedure (3) and the modified methods of the present study were used as below.

The existing procedures (3): The protein sample was made up to $5 \mu \mathrm{g} / \mu \mathrm{l}$ in $450 \mu \mathrm{l}$ with rehydration buffer [8 M urea, $2 \%$ (w/v) CHAPS, 0.5\% (v/v) of pH 3.0-10.0 NL IPG buffer (GE Healthcare)] containing $1 \%$ or $2 \%$ DTT. Additionally, an extra paper soaked with $1 \%$ DTT was placed near the cathode during 1D IEF. The mixtures were applied to Immobiline DryStrip gels (IPG strips; pH 3-10 NL, 24 cm; GE Healthcare) by in-gel rehydration for $16 \mathrm{~h}$ at room temperature in an immobiline DryStrip Reswelling Tray (GE Healthcare).

Modified methods: Reduction and alkylation of proteins was performed prior to IEF. The protein samples $(5 \mu \mathrm{g} / \mu \mathrm{l})$ was pre-reduced and alkylated by one of the six methods shown in Table I. The mixtures were made up to $450 \mu 1$ with rehydration buffer and applied to the IPG strips using the same procedure as previously described.

$1 D I E F$. The IPG strips were transferred to an Ettan IPGphor II Manifold (GE Healthcare). IEF was initiated at a low voltage (200 V, 1 h; step-n-hold, $500 \mathrm{~V}, 1$ h; step-n-hold, $1,000 \mathrm{~V}, 1 \mathrm{~h}$; step-n-hold), and then raised to $10,000 \mathrm{~V}$ for $6 \mathrm{~h}$, with the current limited to a maximum of $75 \mu \mathrm{A} / \mathrm{strip}$ throughout the procedure. The strips were focused for 40,000 , $50,000,70,000$ and $80,000 \mathrm{Vhr}$, respectively.

$2 D S D S-P A G E$. The focusing IPG strips were immediately equilibrated in SDS equilibration buffer [6 $\mathrm{M}$ urea, 75 mM Tris- $\mathrm{HCl}$ (pH 8.8), 30\% glycerol (v/v), 2\% SDS (w/v), $0.002 \%$ (w/v) bromophenol blue] containing $10 \mathrm{mg} / \mathrm{ml}$ DTT for $15 \mathrm{~min}$, and thereafter in the SDS equilibration buffer containing $25 \mathrm{mg} / \mathrm{ml}$ IAA for $15 \mathrm{~min}$. Following equilibration, proteins were separated by $12.5 \%$ SDS-PAGE, which was run until the bromophenol blue dye reached the end of the gel.

Image analysis. Following 2-DE separation, the gels were fixed for $>30 \mathrm{~min}$ in $40 \%$ ethanol and $10 \%$ acetic acid, and stained using a PlusOne Silver Staining kit (GE Healthcare). The stained gels were then scanned with an Image Scanner III (GE Healthcare) and images of the spots were automatically analyzed using ImageMaster 2D Elite software (GE Healthcare).

Protein identification by MALDI-TOF/TOF. The protein spots of interest were excised from the silver-stained gels and subjected to trypsin digestion, according to the methods of Shevchenko et al (6). The digested peptides were extracted from the excised gel pieces and analyzed using an autofle ${ }^{\mathrm{TM}}$ speed MALDI-TOF/TOF system (Bruker Daltonics, Bremen Germany).

For the acquisition of mass spectra, a thin layer of matrix (40 $\mathrm{mg} / \mathrm{ml} \alpha$-cyano-4-hydroxycinnamic acid in 98\% acetone) was deposited on an MTP AnchorChip ${ }^{\mathrm{TM}} 384$ MALDI target (800 $\mu \mathrm{m}$ diameter; Bruker Daltonics). One microliter of the extracted peptides was spotted onto a thin layer of the matrix solution on the target plate and allowed to air dry. MALDI TOF/TOF MS data were acquired using FlexControl 2.4 (Bruker Daltonics) and analyzed using FlexAnalysis 2.4 (Bruker Daltonics). The generated peak list was searched against the SwissProt Mus musculus protein database (SwissProt 57.1; 462,764 sequences, 163,773,385 residues) using in-house MASCOT Server software, version 2.3 (Matrix Science, London, UK) with the following parameters: cysteine carbaminomethylation and methionine oxidation as fixed modification and variable modification, respectively; precursor mass tolerance, $50 \mathrm{ppm}$; MS/MS mass tolerance, 
Table I. Different combinations of conditions for 2-DE.

\begin{tabular}{|c|c|c|c|c|c|c|}
\hline \multirow[b]{2}{*}{ Combination } & \multicolumn{3}{|c|}{ Treatment per $5 \mu \mathrm{g} / \mu 1$ protein } & \multirow[b]{2}{*}{ Temperature } & \multirow[b]{2}{*}{ Time } & \multirow[b]{2}{*}{ Quality of image } \\
\hline & DTT & IAA & DTT & & & \\
\hline I & $10 \mathrm{mM}$ & $40 \mathrm{mM}$ & $40 \mathrm{mM}$ & On ice & $0.5 \mathrm{~h}$ & $\begin{array}{l}\text { Low resolution and } \\
\text { horizontal streaks }\end{array}$ \\
\hline II & $10 \mathrm{mM}$ & $40 \mathrm{mM}$ & $40 \mathrm{mM}$ & On ice & $1 \mathrm{~h}$ & $\begin{array}{l}\text { High resolution and more } \\
\text { protein spots }\end{array}$ \\
\hline III & $10 \mathrm{mM}$ & $40 \mathrm{mM}$ & $40 \mathrm{mM}$ & On ice & $1.5 \mathrm{~h}$ & $\begin{array}{l}\text { High resolution and more } \\
\text { protein spots }\end{array}$ \\
\hline IV & $10 \mathrm{mM}$ & $40 \mathrm{mM}$ & $40 \mathrm{mM}$ & $24^{\circ} \mathrm{C}$ & $1 \mathrm{~h}$ & $\begin{array}{l}\text { Low resolution and } \\
\text { horizontal streaks }\end{array}$ \\
\hline V & $10 \mathrm{mM}$ & $10 \mathrm{mM}$ & $10 \mathrm{mM}$ & On ice & $1 \mathrm{~h}$ & $\begin{array}{l}\text { Low resolution and } \\
\text { horizontal streaks }\end{array}$ \\
\hline VI & $20 \mathrm{mM}$ & $80 \mathrm{mM}$ & $80 \mathrm{mM}$ & On ice & $1 \mathrm{~h}$ & $\begin{array}{l}\text { Low resolution; horizontal } \\
\text { streaks; strip was burned }\end{array}$ \\
\hline
\end{tabular}

2-DE, two-dimensional gel electrophoresis; DDT, dithiothreitol; IAA, iodoacetamide.

$0.5 \mathrm{Da}$; and a maximum of one missed cleavage was allowed. Proteins were only identified when the ion score was above the sequence identity threshold.

\section{Results}

Optimization of the protein extraction methods. The quality of 2-DE analysis largely depends on the quality of sample preparation during protein extraction. Unnecessary procedures should be avoided to increase the reproducibility and minimize modifications that may result in artifactual spots on 2D gels. The present study compared four protein extraction methods in terms of protein yield and processing time (Table II). In general, protein extraction by grinding in liquid nitrogen, sonication or homogenization was highly time-consuming, with a low throughput and low protein yield. Extraction using a TissueLyser yielded the highest amount of protein within a minimal processing time. In addition, 12 samples were processed simultaneously. Therefore, this optimized method was adapted for the subsequent 2-DE analysis.

Clean-up of protein samples. Following protein extraction, contaminants such as salts, lipids, nucleic acids and detergents must be removed to prevent horizontal streaking during IEF. Proteolytic enzymes must also be inhibited to prevent non-specific protein degradation (7). The present study used a 2-D Clean-Up kit and acetone precipitation for contaminant removal (Fig. 1). Prior to sample clean-up, 1,478 protein spots were detected and extensive horizontal streaking was clearly observed (Fig. 1A). Following purification with the 2-D Clean-Up kit, 2,000 protein spots were detected and the horizontal streaking was markedly reduced. The gel image also provided higher resolution when compared with the raw sample (Fig. 1B). On the other hand, acetone precipitation minimizes protein degradation by denaturing most of the
Table II. Comparison of protein yield and processing time for four protein extraction conditions with urea/thiourea lysis buffer.

\begin{tabular}{lcc}
\hline Conditions & $\begin{array}{c}\text { Processing time } \\
(\mathrm{min} / \mathrm{no} \text { of samples })\end{array}$ & $\begin{array}{c}\text { Protein yield } \\
(\mu \mathrm{g} / \mathrm{mg})\end{array}$ \\
\hline TissueLyser & $2 / 12$ & 100 \\
Homogenization & $2 / 1$ & 20 \\
Grinding & $1 / 1$ & 70 \\
Sonication & $2 / 1$ & 80 \\
\hline
\end{tabular}

proteolytic enzymes and removes contaminants contained in the tissue samples. However, the incomplete precipitation and resolubilization of proteins results in non-specific loss of proteins (3). As such, only 1,657 protein spots were detected and the resolution was decreased by using ice-cold acetone precipitation in the present study (Fig. 1C). Therefore, the 2-D Clean-Up kit was used in the subsequent 2-DE analysis, which may achieve $20 \%$ more protein spots.

Influences of the buffer used for solubilization of proteins. The buffer used for the extraction and solubilization of proteins in the tested samples also influenced the quality and reproducibility of the 2-D gel images. Urea lysis buffer has been reported to be insufficient for solubilizing highly hydrophobic proteins, including membrane proteins (8). By contrast, the addition of thiourea to the lysis buffer improves the solubilization of proteins (8). As shown in Fig. 2, using urea/thiourea lysis buffer in the sample preparation allowed more protein spots to be identified and provided higher gel resolution than when using urea lysis buffer. When using urea lysis buffer, 2,000 protein spots were detected (Fig. 2A), while 2,500 protein spots were detected when urea/thiourea lysis buffer was used (Fig. 2B). Therefore, urea/thiourea lysis buffer 
A

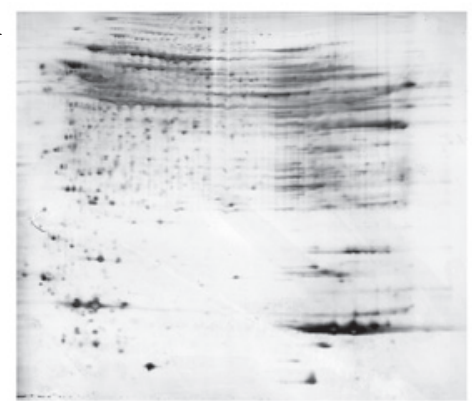

B

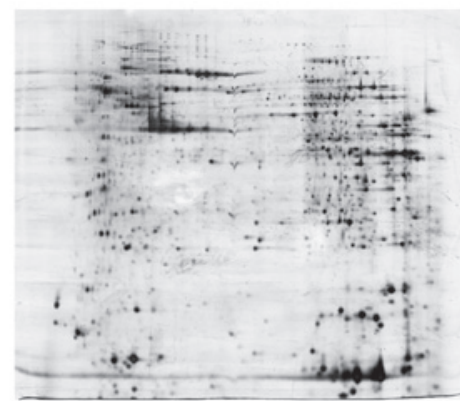

C

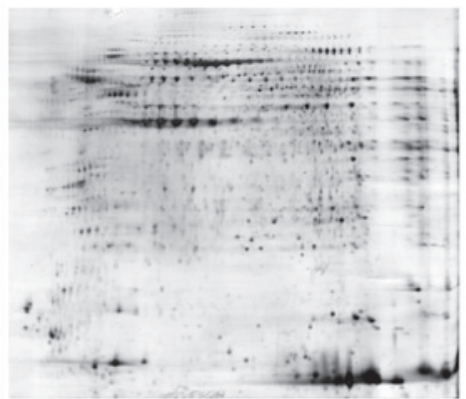

Figure 1. 2-D gel images of proteins from mouse tumor samples produced (A) without precipitation or with (B) precipitation using a 2-D Clean-Up kit or (C) precipitation with ice-cold acetone. The proteins were separated on 24-cm IPG strips (pH 3-10 NL). 2-D, two-dimensional; IPG, immobilized pH gradient.

A

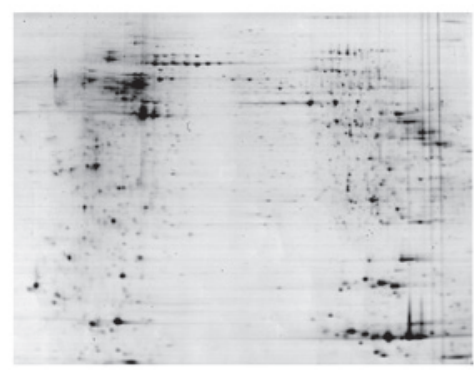

B

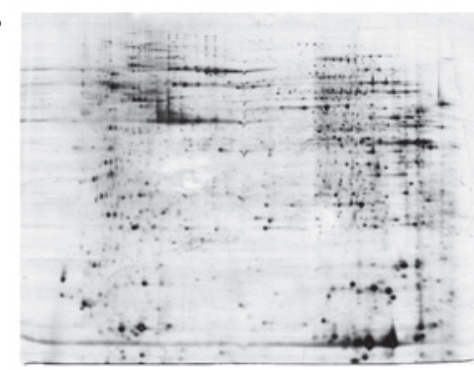

Figure 2. 2-D gel images of proteins from mouse tumor samples prepared with (A) urea lysis buffer or (B) urea/thiourea lysis buffer. 2-D, two-dimensional.

A
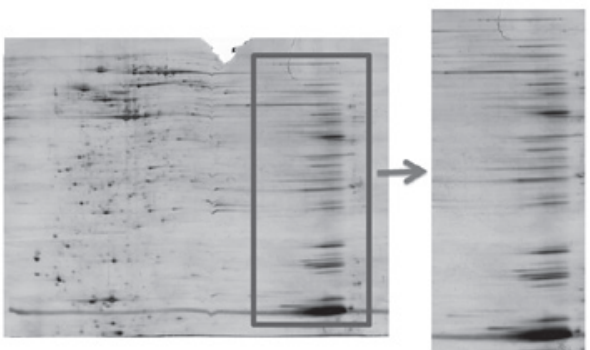

$\mathbf{C}$

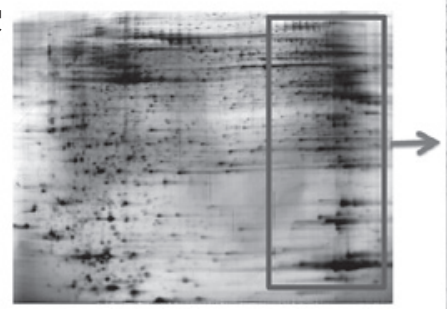

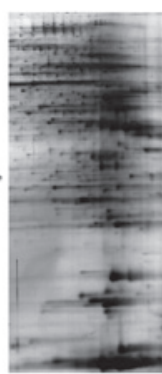

B

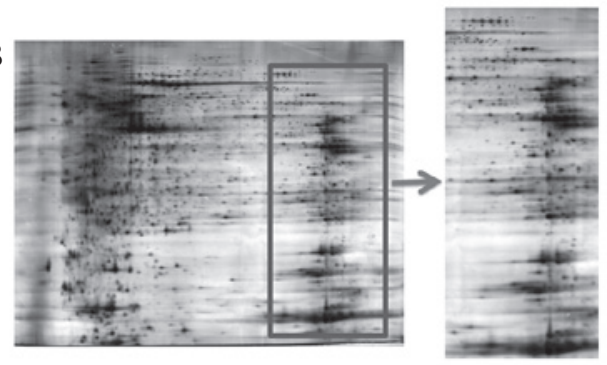

D
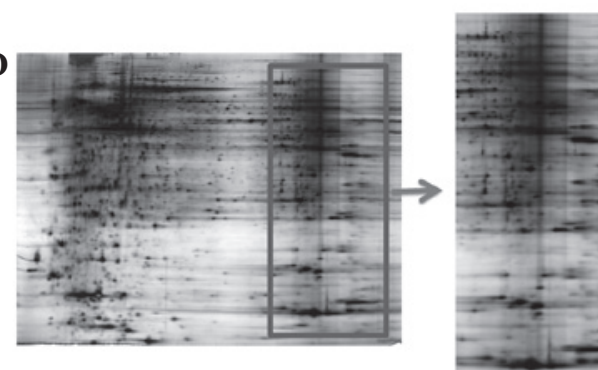

Figure 3. 2-D gel images of proteins from mouse tumor samples prepared with different focusing conditions. Tumor proteins (400 $\mu \mathrm{g})$ were separated using the existing procedure with $1 \%$ DTT on 24-cm IPG strips (pH 3-10 NL). The focusing conditions used were as follows: (A) 40,000 Vhr; (B) 50,000 Vhr; (C) 60,000 Vhr; and (D) 70,000 Vhr. 2-D, two-dimensional; DDT, dithiothreitol; IPG, immobilized pH gradient. 

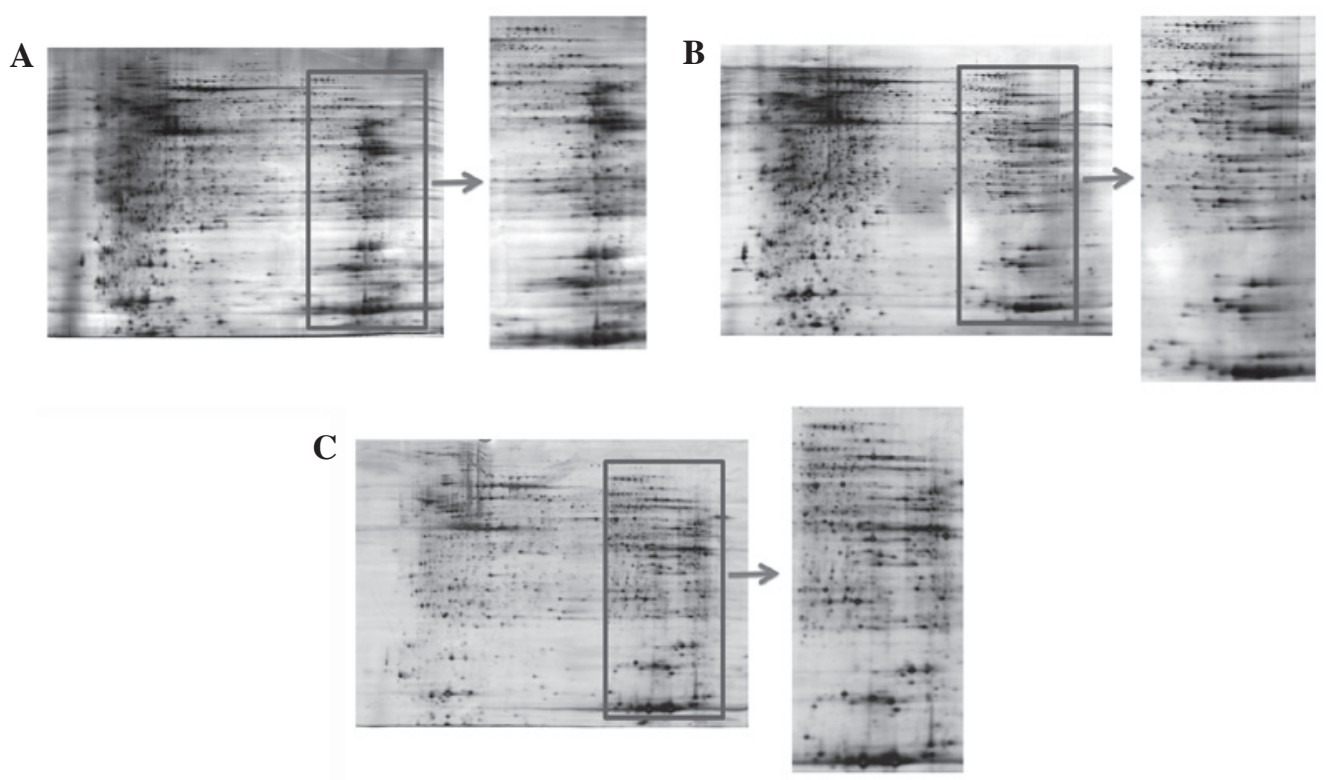

Figure 4. 2-D gel images of proteins from mouse tumor samples prepared with different amounts of DTT in the rehydration buffer. Tumor proteins (400 $\mu \mathrm{g})$ were separated using the existing procedure on 24-cm IPG strips (pH 3-10 NL) for 50,000 Vhr. The amount of DTT in the rehydration buffer was (A) 1\%, (B) $2 \%$ or (C) $1 \%$ with an extra paper soaked in DTT near the cathode. 2-D, two-dimensional; DDT, dithiothreitol; IPG immobilized pH gradient.

was used in the subsequent analysis, which may achieve $20 \%$ more protein spots.

\section{Optimization of the conditions during electrophoresis}

In the IEF procedures of electrophoresis, the focusing time and pre-reduction processes are the pivotal factors in protein separation and detection by 2-D gel analysis.

Focusing time. The focusing time strongly affects the attainment of steady-state IEF patterns. It is also an essential factor in achieving high quality and reproducible 2-D gel images. Insufficient focusing induces horizontal and vertical streaking, while overfocusing may result in distorted protein patterns and horizontal streaking at the basic gel end, leading to loss of protein spots $(9,10)$. In the present study, different focusing times were compared (Fig. 3). When the sample was focused for 40,000 $\mathrm{Vhr}$, incomplete focusing and heavy horizontal streaking were observed in the 2-D gel image (Fig. 3A), indicating that the focusing duration is insufficient for most of the proteins to achieve steady-state focusing. When the samples were focused for 60,000 and $70.000 \mathrm{Vhr}$, the image quality around neutral $\mathrm{pH}$ was acceptable but heavy horizontal streaking was observed in the areas near the cathode electrodes (Fig. 3C and D), indicating overfocusing. By using $50,000 \mathrm{Vhr}$, optimal gel resolution and minimized streaking were observed (Fig. 3B). Collectively, the results indicated that $50,000 \mathrm{Vhr}$ was optimal for the 2-D gel protein analysis of tumor tissue samples.

Reduction and alkylation of unexpected proteins prior to $I E F$. The reduction process is another pivotal factor in protein separation and detection by 2-D gel analysis. DTT is a strong reducing agent, which is often adopted for breaking disulfide bonds and unfolding protein secondary and tertiary structures. Depletion of DTT during IEF may induce horizontal streaking due to protein re-oxidation, which is particularly common in large gels (3). To achieve a well-focused 1D separation, protein extracts in rehydration buffer and 1 or 2\% DTT were compared.
Increasing the percentage of DTT in the rehydration buffer reduced the horizontal streaking and improved gel resolution at the cathode, although it also resulted in distorted protein patterns (Fig. 4A and B). In addition, a study has demonstrated that a shortage of the reducing agent is avoidable by placing an extra paper soaked with DTT near the cathode (11). Nevertheless, each of these two methods alone was insufficient in diminishing horizontal streaking, while improved resolution and inhibition of re-oxidation of the sulfhydryl groups, produced by the dynamic loss of DTT, was achieved with $1 \%$ DTT when an extra paper soaked with $1 \%$ DTT was used near the cathode (Fig. 4C).

A previous study demonstrated that the reduction and alkylation of proteins prior to IEF greatly reduces the streaking caused by IEF (12). Following reduction of the disulfide bonds by DTT, IAA was used to alkylate the free thiol groups of cysteine residues to prevent their re-oxidation (back reaction) during electrophoresis. The excess IAA was neutralized by adding an equimolar amount of DTT to prevent overalkylation. However, the protocol for pre-reduction and alkylation has varied greatly in different studies and the experimental conditions have not yet been clearly optimized $(12,13)$. Thus, all factors, in terms of the time and temperature of the reaction, as well as the ratio of DTT/IAA, that may influence 2-D gel analysis were systematically examined in the present study (Table I). The results indicate that reduction and alkylation with DTT/IAA/DTT $(10 \mathrm{mM} / 40$ $\mathrm{mM} / 40 \mathrm{mM}$ to $5 \mu \mathrm{g} / \mu \mathrm{l}$ protein) on ice for $1 \mathrm{~h}$ for each step prior to IEF achieves higher resolution and improved protein separation (Fig. 5).

Protein detection using two electrophoresis conditions. To investigate whether reduction and alkylation prior to IEF affect the final protein identification, matched protein spots from gels prepared with or without pre-reduction and alkylation were subjected to gel-based protein identification. A total 
Table III. Comparison of the proteins identified using two different electrophoresis conditions.

Identification

\begin{tabular}{rll}
\cline { 2 - 3 } Spot no. & \multicolumn{1}{c}{ Previous conditions } & \multicolumn{1}{c}{ Modified conditions } \\
\hline 1 & - & \\
2 & 40 - -tropomyosin \\
3 & Actin & 40S ribosomal protein SA \\
4 & - & Actin \\
5 & Galactokinase & p53-induced protein phosphatase 1 \\
6 & Vesicle protein sorting 26B & Galactokinase \\
7 & Cytochrome P450 & Vesicle protein sorting 26B \\
8 & Thioredoxin OS & Cytochrome P450 \\
9 & Transketolase & Thioredoxin OS \\
10 & - & Transketolase \\
11 & - & Pyruvate kinase isozyme M2 \\
12 & - & ATP synthase subunit $\alpha$ \\
13 & SID1 transmembrane family member 2 precursor & Vacuolar ATP synthase subunit E \\
\hline
\end{tabular}
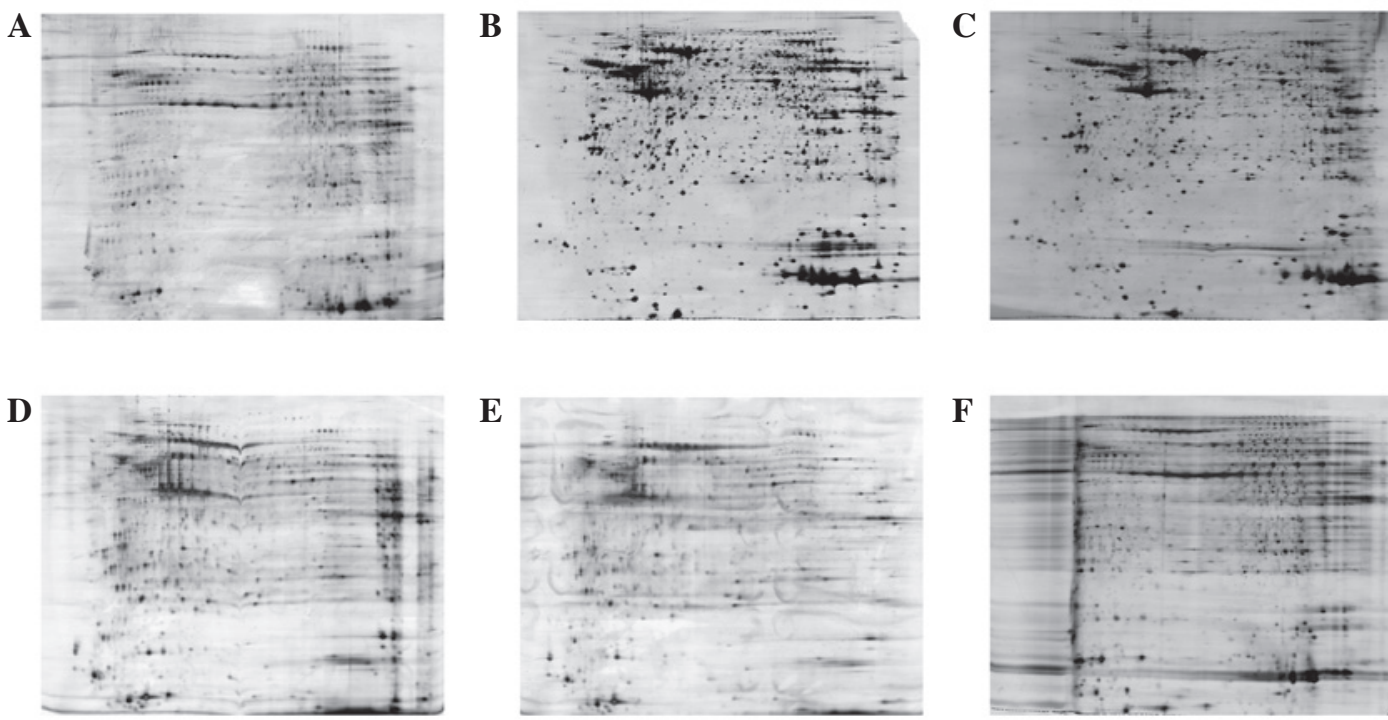

Figure 5. 2-D gel images of the reduced and alkylated proteins in mouse tumor samples with different reaction conditions. Tumor tissue proteins (400 $\mu \mathrm{g})$ were separated on 24-cm IPG strips (pH 3-10 NL) for 50,000 Vhr. The amount of DTT/IAA/DTT and the incubated temperature and time for reduction and alkylation were as follows: (A) $10 \mathrm{mM} / 40 \mathrm{mM} / 40 \mathrm{mM}$ on ice for $0.5 \mathrm{~h}$; (B) $10 \mathrm{mM} / 40 \mathrm{mM} / 40 \mathrm{mM}$ on ice for $1 \mathrm{~h}$; (C) $10 \mathrm{mM} / 40 \mathrm{mM} / 40 \mathrm{mM}$ on ice for $1.5 \mathrm{~h}$; (D) $10 \mathrm{mM} / 40 \mathrm{mM} / 40 \mathrm{mM}$ at room temperature for $1 \mathrm{~h}$; (E) $10 \mathrm{mM} / 10 \mathrm{mM} / 10 \mathrm{mM}$ on ice for $1 \mathrm{~h}$; and (F) $20 \mathrm{mM} / 80 \mathrm{mM} / 80 \mathrm{mM}$ on ice for $1 \mathrm{~h}$. 2-D two-dimensional; IPG immobilized pH gradient; DDT, dithiothreitol; IAA, iodoacetamide.
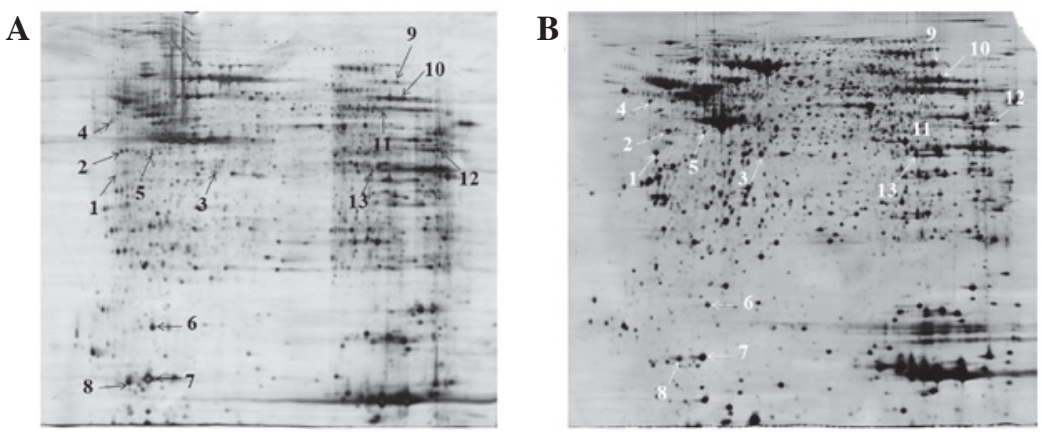

Figure 6. 2-D gel images from two sets of electrophoresis conditions: (A) Previously reported electrophoresis conditions and (B) modified electrophoresis conditions (with reduction and alkylation of proteins prior to electrophoresis). 2-D, two-dimensional. 
of 13 matched spots were excised from different areas of the 2-D gels for analysis (Fig. 6). Only eight spots (numbers 2, 3, $5,6,7,8,9$ and 13) from the existing procedure were successfully identified, while all spots were identifiable following pre-reduction and alkylation (Table III). It was not possible to identify confidently spot numbers $1,4,10,11$ and 12 from the existing procedure as multiple overlapping peptides were recovered due to horizontal streaking. The results indicate that the modified conditions of the present study are more effective for finding biomarkers and molecular targets.

\section{Discussion}

Overall, the present study has optimized the sample preparation and $1 \mathrm{D}$ separation conditions for the 2-DE analysis of tumor tissue samples. Compared with the previously reported conditions, the present study demonstrated that tumor tissue proteins extracted by a bead mill TissueLyser LT with urea/thiourea lysis buffer, followed by 2-D Clean-Up kit purification produced optimal throughput and protein yielding rates. In addition, the reduction and alkylation of proteins with optimal focusing conditions prior to IEF on a 24-cm strip was demonstrated to be effective in preventing the horizontal streaking caused by oxidation and in identifying biomarkers and molecular targets. In conclusion, the modified conditions and protocols of the present study allowed the 2-DE analysis of tumor tissue proteins with enhanced reproducibility and sensitivity and higher 2-DE protein recovery and resolution.

\section{Acknowledgements}

This study was supported by the Science and Technology Development Fund, MSAR (Project code: 035/2011/A2).

\section{References}

1. Klose J: Protein mapping by combined isoelectric focusing and electrophoresis of mouse tissues. A novel approach to testing for induced point mutations in mammals. Humangenetik 26: 231-243, 1975.

2. O'Farrell PH: High resolution two-dimensional electrophoresis of proteins. J Biol Chem 250: 4007-4021, 1975.

3. Görg A, Obermaier C, Boguth G, et al: The current state of two-dimensional electrophoresis with immobilized $\mathrm{pH}$ gradients. Electrophoresis 21: 1037-1053, 2000.

4. Campostrini N, Areces LB, Rappsilber J, et al: Spot overlapping in two-dimensional maps: a serious problem ignored for much too long. Proteomics 5: 2385-2395, 2005.

5. Galvani M,Hamdan M and Righetti PG: Investigating the reaction of a number of gel electrophoresis cross-linkers with beta-lactoglobulin by matrix assisted laser desorption/ionization-mass spectrometry. Electrophoresis 21: 3684-3692, 2000.

6. Shevchenko A, Tomas H, Havlis J, Olsen JV and Mann M: In-gel digestion for mass spectrometric characterization of proteins and proteomes. Nat Protoc 1: 2856-2860, 2006.

7. Herbert B, Righetti P, Citterio A and Boschetti E: Sample preparation and prefractionation techniques for electrophoresis-based proteomics. In: Proteome Research: Concepts, Technology and Application. Wilkins, MR, Appel, RD, Williams, KL and Hochstrasser DF (eds). 2nd edition. Springer, Heidelberg Berlin, pp15-40, 2007.

8. Rabilloud T: Solubilization of proteins in 2-D electrophoresis. An outline. Methods Mol Biol 112: 9-19, 1999.

9. Görg A, Postel W and Günther S: The current state of two-dimensional electrophoresis with immobilized $\mathrm{pH}$ gradients. Electrophoresis 9: 531-546, 1988.

10. Görg A: Two-dimensional electrophoresis. Nature 349: 545-546, 1991.

11. Görg A, Boguth G, Obermaier C, Posch A and Weiss W: Two-dimensional polyacrylamide gel electrophoresis with immobilized $\mathrm{pH}$ gradients in the first dimension (IPG-Dalt): the state of the art and the controversy of vertical versus horizontal systems. Electrophoresis 16: 1079-1086, 1995.

12. Herbert B, Galvani M, Hamdan M, et al: Reduction and alkylation of proteins in preparation of two-dimensional map analysis: why, when, and how? Electrophoresis 22: 2046-2057, 2001.

13. Candiano G, Bruschi M, Musante L, et al: Blue silver: a very sensitive colloidal Coomassie G-250 staining for proteome analysis. Electrophoresis 25: 1327-1333, 2004. 